\title{
Justice-Based Opposition to Social Policies: Is It Genuine?
}

\author{
D. Ramona Bobocel, Leanne S. Son Hing, Liane M. Davey, David J. Stanley, and Mark P. Zanna \\ University of Waterloo
}

\begin{abstract}
Three studies examined whether the concern for justice can be a genuine determinant of attitudes toward affirmative action (AA) or whether justice-based opposition merely masks prejudice. In line with the hypothesis of justice as a cause, we found that, independent of their level of prejudice, people were opposed to AA programs that violate distributive and procedural justice norms, as a result of genuine beliefs in the principles of faimess that the programs violate. Nevertheless, in line with the hypothesis of justice as a rationalization, we also found that people's prejudice level was positively associated with opposition to AA programs that were not explicitly justice violating; moreover, the effect of prejudice was mediated through the tendency to construe these programs as justice violating. The present research has implications for understanding attiudes toward social policies where it is possible that justice concerns could be a genuine source of opposition or a rationalization of prejudice.
\end{abstract}

In recent years, the societal debate about policies on such issues as immigration, affirmative action (AA), or bilingualism has become increasingly polarized. Consider the case of AA: On the one hand, many opponents claim that AA is unfair, because such policies consider people's membership in particular social categories in addition to traditional indices of deservingness when allocating desired outcomes (e.g., jobs, promotions, or university admission). On the other hand, many advocates allege that people who oppose AA in the name of fairness are in fact prejudiced. Whereas some people clearly recognize that prejudice and justice concerns might be independent sources of opposition to a number of social policies, much of the rhetoric suggests that what is purportedly justice-based opposition is not genuine but rather a rationalization of prejudice. ${ }^{1}$

Is the concern for justice a genuine determinant of attitudes toward social policies, such as AA, or do claims of unfaimess

D. Ramona Bobocel, Leanne S. Son Hing, Liane M. Davey, David J. Stanley, and Mark P. Zanna, Department of Psychology, University of Waterloo, Waterloo, Ontario, Canada. Leanne S. Son Hing and Liane M. Davey contributed equally to this article.

This project was funded by research grants from the Social Sciences and Humanities Research Council of Canada awarded to D. Ramona Bobocel and to Mark P. Zanna.

Earlier versions of this article were presented at the Annual Meeting of the Society for the Psychological Study of Social Issues, Division 9 of the American Psychological Association (reporting Study 1), Ann Arbor, Michigan, May 1996, and at the International Network for Social Justice Research, 5th Biennial Meeting (reporting Study 2), Potsdam, Germany, July 1997.

We thank our research assistants for their exemplary work on various aspects of the project: Adam Zanna (for conducting Study 1), Bar Hochman, Andrea Bourne, and Louise Chapman. We also gratefully acknowledge Erik Woody, Mark Fillmore, and John Michela for advice regarding statistical issues. Finally, thanks are extended to Russell Cropanzano for helpful comments on an earlier version of this article.

Correspondence concerning this article should be addressed to $D$. Ramona Bobocel, Department of Psychology, University of Waterloo, Waterloo, Ontario, Canada N2L 3G1. Electronic mail may be sent to rbobocel@watarts.uwaterloo.ca. merely mask less socially desirable motivations, such as prejudice? On the basis of a growing literature showing that the concern for justice can influence people's reactions in a variety of domains (e.g., legal, social, organizational; for reviews, see Cropanzano \& Greenberg, 1997; Lind \& Tyler, 1988; Tyler \& Lind, 1992), it is reasonable to expect it can be a genuine determinant of opposition to AA. In the present article, we report our research that was designed to directly address the question of the concern for justice as a genuine cause of opposition to AA versus a rationalization of prejudice. In the following sections, first we define AA, then we briefly review justice theory and research that led to our predictions.

\section{Definition of Affirmative Action and Effect of Policy Characteristics on Attitudes}

AA has been defined elsewhere as "a body of policies and procedures designed to eliminate employment discrimination against women and ethnic minorities, and to redress the effects of past discrimination" (p. vii; Kravitz et al., 1997). Given that AA is thus a broad concept, it is not surprising that specific programs falling under its umbrella often have very different features.

In general, however, AA programs vary in the extent to which target-group members are treated differently than non-targetgroup members. For example, at one end of a spectrum of workplace AA programs are those that objectively do not involve preferential treatment. These equal treatment programs (e.g., mentorship policies, paternity and maternity leave) are designed to remove systemic barriers. Although such programs might be of greater benefit to target-group members because of their special needs, they offer services to all employees-target-

\footnotetext{
${ }^{1}$ The process of rationalization to which we are referring might occur in one or more of several related ways. For example, prejudiced individuals might claim, post hoc, that $A A$ is unfair in an effort to justify existing attitudes. Alternatively, prejudiced individuals might be primed to perceive AA policies as unfair in a more "on line" fashion. Arguably, these mechanisms are inextricably linked, and we do not attempt to disentangle them here.
} 
and non-target-group members alike. At the other end of the spectrum are preferential treatment programs, which use group membership as a criterion in allocating desired outcomes. With strong forms of preferential treatment, the traditional principle of meritocracy is violated in that group membership is considered even if a target-group member is relatively less qualified than a competing non-target-group member. In the middle of the spectrum are differential treatment programs, which treat target- and non-target group members differently but do not, strictly speaking, violate meritocracy. For example, group membership might affect selection decisions only if all elsenamely, qualifications - is equal. Although traditionally, researchers have considered the latter program as a mild form of preferential treatment, we distinguish the terms preferential and differential treatment and restrict usage of preferential treatment to programs that violate meritocracy (for more on specific programs, see Kravitz, 1995; Kravitz \& Platania, 1993; Kravitz, Stinson, \& Mello, 1994; Son Hing, 1997).

In numerous studies, it has been shown that both non-targetand target-group members react less favorably to preferential treatment programs than to nonpreferential programs (e.g., Chacko, 1982; Clayton \& Tangri, 1989; Kravitz, 1995; Kravitz \& Platania, 1993; Kravitz et al., 1994; Nacoste, 1985; Nosworthy, Lea, $\&$ Lindsay, 1995). Nevertheless, as noted by others (e.g., Esses \& Seligman, 1996), a problem with the past research is that, often, the characteristics of the program being evaluated are not clearly specified. By not clearly specifying the characteristics of the AA program, participants are free to define it in a variety of ways, and, as a consequence, it is difficult to summarize past research on determinants of AA attitudes. As will be seen, the issue of program characteristics is central to our research, because we expected that the determinants of opposition should differ depending on the policy specifics.

\section{The Concern for Justice: Cause or Rationalization?}

A number of scholars have discussed the relevance of people's perceptions of the fairness of AA programs in predicting opposition (e.g., Barnes Nacoste, 1994; Clayton \& Tangri, 1989; Crosby, 1994; Heilman, 1994; Kinder \& Sanders, 1990; Kravitz, 1995; Nacoste, 1985; Nosworthy et al., 1995; Tougas, Joly, Beaton, \& St. Pierre, 1996; Turner \& Pratkanis, 1994). Indeed, several studies have demonstrated that, as people's perceptions of the fairness of AA decrease, their opposition increases (e.g., Kravitz, 1995; Nosworthy et al., 1995; Tougas \& Veilleux, 1988). Other studies have shown that, in general, people perceive AA to be more unfair the more that preferential treatment is involved (e.g., Chacko, 1982; Clayton \& Tangri, 1989; Kravitz \& Platania, 1993; Nacoste, 1985, 1987).

Is opposition purportedly deriving from fairness concerns actually rationalized prejudice? Presumably, the possibility exists. Indeed, research using both classical (i.e., a belief in innate interracial differences and the superiority of one's own race) and symbolic (i.e., a more subtle mixture of anti-Black affect and an adherence to traditional values, such as individualism and hard work; Kinder \& Sears, 1981; McConahay, 1986) forms of racism suggests that prejudice relates to negative attitudes toward AA (e.g., Jacobson, 1985; Kluegel \& Smith, 1983; Sidanius, Pratto, \& Bobo, 1996). Moreover, in line with research on racism, Tougas, Brown, Beaton, and Joly (1995) have found that neo-sexism--a more subtle form of sexism-predicts opposition toward AA.

Traditionally, however, AA has been undefined in past prejudice research. Although there is little systematic research, some recent evidence suggests that prejudice might relate to AA attitudes differentially, as a function of program characteristics. For example, in a large survey aimed at validating a unidimensional conceptualization of forms of racism, Kleinpenning and Hagendoom (1993) found that Dutch secondary school students' scores on racism were correlated more highly with their opposition to a question about equal opportunity in society than to a question about preferential treatment in job hiring.

Kleinpenning and Hagendoorn's (1993) results might seem counterintuitive at first glance-that is, because AA aims to help women and visible minorities, we might expect that people's level of prejudice should predict opposition regardless of program characteristics. On closer scrutiny, however, their finding makes sense. In particular, if we assume that the concern for justice is an independent source of opposition to AA, then it is reasonable to expect that the difference between those high and low in prejudice might be smaller in the context of a preferential treatment, as compared with an equal opportunity program. In other words, given that preferential treatment violates justice principles that are generally valued, people will tend to be opposed regardless of their prejudice level (i.e., both those high and low in prejudice will tend to be opposed). Consequently, respondents' level of prejudice would predict opposition less strongly in the context of justice-violating programs (e.g., preferential treatment) versus non-justice-violating programs (e.g., equal opportunity). In contrast, individual differences in justice beliefs would predict opposition to justice-violating programs more strongly than to non-justice-violating programs. In summary, if the concern for justice is distinguishable from prejudice as a source of opposition, then the strength of prejudice and justice beliefs as predictors of opposition to AA should be moderated by specific program characteristics.

A recent study by Nosworthy et al. (1995) provides evidence to support the notion that AA program characteristics might moderate the determinants of opposition. More specifically, the researchers examined the roles of prejudice (measured by a traditional racism index developed by the authors) and justice beliefs (measured by Rasinski's 1987 Proportionality Scale and Rubin \& Peplau's 1975 Just World Scale ) in predicting students' attitudes toward four AA programs designed to increase representation of Black students at their university: targeted advertising, increased funding, a change in grade requirements, and enrollment quotas.

As might be expected on the basis of past research, Nosworthy et al. ( 1995 ) found that respondents' perceptions of program fairness were a significant, unique (negative) predictor of endorsement, with the smallest contribution in the ads program and the greatest contribution in the quota program. Consistent with this finding, in a regression analysis to examine the unique roles of prejudice and individual differences in justice beliefs as predictors of endorsement, respondents' justice beliefs - when indexed by the Just World Scale-predicted endorsement (negatively) most strongly in the quota program as compared with 
the ads program. ${ }^{2}$ Given that perceptions of program fairness predicted most strongly in the quota program, it follows that individual differences in justice beliefs should also predict most strongly in that program. (In other words, if participants differ systematically in the extent to which they believe in the principle of faimess that the quota program is perceived to violate, then, logically, such an individual difference should predict endorsement.)

Finally, in an analysis regressing participants' racial affect, self- and group interest, and perceptions of program fairness on endorsement of the four AA programs, Nosworthy et al. (1995) found results similar to those of Kleinpenning and Hagendoorn (1993) noted earlier. That is, racism contributed most strongly and, indeed, accounted for unique variance over and above fairness perceptions only within the mildest AA program (i.e., targeted ads).

Together, the findings of Kleinpenning and Hagendoorn (1993) and those of Nosworthy et al. (1995) are in line with the idea that justice can be a genuine cause of opposition. That is, to the extent that there are meaningful psychological differences among various AA programs in the extent to which they violate justice principles, then individual differences in justice beliefs should predict opposition when the program violates justice principles and not when the program upholds those principles. As a consequence, prejudice should predict opposition less strongly for programs that violate justice principles relative to programs that do not. If, in contrast, the concern for justice is not a true determinant of attitudes but instead a rationalization of prejudice, then respondents' scores on prejudice should predict opposition regardless of whether the AA program violates or upholds justice principles, and justice beliefs should not predict opposition differentially across type of program.

The purpose of our research was to test directly the preceding logic. As noted by others (e.g., Nosworthy et al., 1995), to do so, we needed to vary systematically the extent to which AA programs "objectively" violated specific justice principles. In the next section, we briefly outline the justice framework that served as the basis for our research.

\section{Distributive and Procedural Justice Theory: An Application to AA}

Although there is some debate over the number of justice dimensions (for reviews, see Cropanzano \& Greenberg, 1997; Greenberg, 1993), the traditional distinction between distributive and procedural justice continues to have both theoretical and applied utility (cf. Cropanzano \& Ambrose, in press). In brief, whereas the concept of distributive justice is concerned with people's perceptions of the faimess of the distribution of resources or outcomes (e.g., Adams, 1965; Homans, 1961; for a review, see Greenberg \& Cohen, 1982), the concept of procedural justice is concerned with the faimess of the procedures by which a distributive allocation norm is implemented (e.g., Leventhal, 1980; Leventhal, Karuza, \& Fry, 1980; Lind \& Tyler, 1988; Thibaut \& Walker, 1975).

As noted by others (e.g., Clayton \& Tangri, 1989; Cohen, 1994; Dovidio, 1996; Esses \& Seligman, 1996; Nacoste, 1987; Smith Winkelman \& Crosby, 1994), AA can be conceptualized from a distributive and procedural justice perspective. That is, given that AA involves the distribution of resources (e.g., jobs, pay, promotions) among groups, distributive justice principles are relevant. More specifically, AA could be perceived as unfair at the distributive level, because people perceive that equity or merit (e.g., Deutsch, 1975, 1985; Lemer, 1977) - the allocation norm generally agreed on in Western culture as appropriate in the workplace - is violated.

AA could also be considered unfair at the procedural level, because people perceive that it violates specific procedural justice criteria, such as consistency across people (e.g., Leventhal, 1980; Leventhal et al., 1980). That is, it could be argued that AA treats target-group and non-target-group members inconsistently in that group status is an advantage for some and a disadvantage for others. Indeed, sensitivity to procedural inconsistency might help to explain why people generally dislike AA programs that give preferential treatment in instances of "tied", merit (e.g., Kravitz \& Platania, 1993). Given that such programs do not allow a less qualified target-group candidate to be favored over a more qualified non-target-group candidate, merit is not violated per se. Thus, it is plausible that participants react negatively because such programs violate the consistency rule of procedural justice.

In summary, concerns about the violation of distributive justice, procedural justice, or both could underlie justice-based objections to AA. To test the question of the concern for justice as a genuine determinant of opposition to $\mathrm{AA}$, we used the distributive-procedural justice framework to make a priori distinctions among AA programs.

\section{Study 1}

We began our research by focusing on distributive justicebased opposition. Specifically, following the logic outlined earlier, we argued that, to the extent that opposition to AA is genuinely determined by the concern for distributive justice, individual differences in the preference for distributions based on merit should predict opposition but only when the merit principle is violated. In other words, people who believe strongly in distributing outcomes on the basis of merit should be more negative about a program that violates meritocracy than those who do not. In the case of a program that does not violate meritocracy, there should be no corresponding difference as a function of people's beliefs in merit. Consequently, and consistent with the findings of Kleinpenning and Hagendoorn (1993) and Nosworthy et al. (1995), prejudice should predict opposition more strongly when the program does not violate merit than when it does. That is, the difference between people high and low in prejudice should be smaller when the program violates merit, because in general people should be more opposed regardless of their level of prejudice; instead of prejudice, people's beliefs in merit should predict opposition.

Therefore, in a first experiment, we measured participants' level of prejudice (sexism) and their beliefs in merit; we then asked them to evaluate one of two AA programs. One was

\footnotetext{
${ }^{2}$ Inexplicably, respondents' scores on the Just World Scale but not the Proportionality Scale correlated significantly with how fair the quota program was perceived to be.
} 
an equal treatment (ET) program, which did not violate the distributive justice principle of equity, and the other was a strong preferential treatment (PT) program, which did. We had three primary predictions. First, in line with past research on program characteristics (e.g., Kravitz \& Platania, 1993; Nosworthy et al., 1995; Tougas \& Veilleux, 1988), we predicted a main effect of program, such that in general participants would be more opposed to the PT than the ET program. Second, although we expected sexist people to be more opposed than nonsexist people overall, we predicted that this would be particularly true for the ET program (i.e., a Sexism $\times$ Program interaction). Finally, we hypothesized that people who believe strongly in merit would be more opposed than those who do not, but only in the case of the PT program (i.e., a Belief in Merit $\times$ Program interaction).

\section{Method}

\section{Participants and Design}

Participants were 56 Canadian students ( 34 men, 22 women) at the University of Waterloo who participated for course credit. ${ }^{3}$ The age range of the participants was 19 to 25 years. Participants were randomly assigned to one of two conditions: type of AA program (ET vs. PT).

\section{Procedure}

Assessment of individual differences. We built on past research on AA by (a) attempting in the design phase to reduce spurious content overlap among our measures of prejudice, justice beliefs, and opposition and (b) obtaining our predictors and the criterion in different settings and at different points in time (cf. Nosworthy et al., 1995). Thus, we collected individual difference data one month prior to participation in the study. The measures, which were counterbalanced for order, were included in a mass-testing booklet distributed in students' classes on the first day of the semester. A total of 214 students completed the masstesting booklet. ${ }^{4}$

We used sexism as our index of prejudice to be consistent with much of the past research on AA conducted in Canada (e.g., Beaton, Tougas, \& Joly, 1996; Tougas, Beaton, \& Veilleux, 1991; Tougas, Brown, Beaton, \& Joly, 1995; Tougas \& Veilleux, 1988). Sexism was assessed with 13 items (rated on a 5-point disagree-agree scale) that were adapted from past research (e.g., Tougas et al., 1995). The scale included statements such as "Career women tend to be more masculine and domineering" (positively keyed) and "Women deserve what they have received from government over the past few years" (negatively keyed). In an effort to maximize internal validity, items from previously published sexism scales that appeared to have substantial content overlap with attitudes toward AA or other relevant constructs were excluded from our index. ${ }^{5}$

Participants also completed the 15-item Belief in Merit (BIM) Scale (Davey, Bobocel, Son Hing, \& Zanna, 1998). This measure was designed to assess individuals' preference for allocations that are based on the distributive justice norm of equity, or the merit principle (Davey, 1995; Davey et al., 1998). Two example items (rated on a 5-point disagree-agree scale) are "In organizations, people who do their job well ought to rise to the top" (positively keyed) and "Sometimes it is appropriate to give a raise to the worker who most needs it, even if he/ she is not the most hard working"' (negatively keyed).

Main study. Approximately 1 month after completing the individual difference measures, the experimenter telephoned a random sample of the students. ${ }^{7}$ The experimenter claimed to be a work-study student employed for the semester at a company called Cochrane Industries. The experimenter told participants that Cochrane Industries (which in fact was a fictitious organization) was planning to implement an AA program and that they were attempting to gauge reactions to different types of programs. To enhance experimental realism, participants were told that their opinions regarding the AA program would be used to aid Cochrane Industries in making their decision about which AA program to implement.

Respondents participated in groups of two to four. To bolster our cover story and reduce suspicion that this was a psychology experiment, this phase of the data collection took place in a room outside of the psychology building, and the experimenter was dressed in a business suit. Participants were asked to read an article titled "Decisions Ahead of Us." The article appeared to be a photocopy of a page from the company's quarterly report. To make gender salient, a picture of a White woman (who was also quoted in the article) was placed in the top righthand corner of the article.

The article stated that Cochrane Industries wished to implement an AA program to meet the goal of "leveling the playing field" for all employees. Further, it stated that Cochrane Industries was investigating the types of AA programs used at other organizations. As an example of a potential AA program that Cochrane Industries could adopt, the article described a program that ostensibly had been implemented at Haines Corporation (also a fictitious company). The details of the program constituted the experimental manipulation. In brief, half of the participants read a description of a preferential treatment program, and the other half read a description of an equal treatment program. (For details, see the Experimental Manipulation section, which follows.)

Following the manipulation, the article then described a woman named Beverly (pictured in the article) who ostensibly was an employee at Haines Corporation. Beverly was quoted as saying "I think it's a great program; it's made a real difference in my life. . . ."

After reading the article, participants (who were assured of anonymity) were asked a number of questions about how employees at Cochrane Industries might feel about the program used at Haines Corporation. Participants were then told that, because their own attitudes could influence how they expect employees to react, they were required to report their personal views so that these could be taken into consideration (see Measures section, which follows). In reality, the questions asking participants to predict how employees might feel served only as filler items and were included to bolster the cover story that this was a real corporate survey rather than a psychological study.

On completion of the dependent variables, participants were thanked, probed for suspicion, debriefed about the purpose of the study, and the deceptions involved were explained thoroughly.

\section{Experimental Manipulation}

Preferential treatment program. In this condition, participants read about a program in which group membership could affect hiring or

\footnotetext{
${ }^{3}$ In all studies reported in this article, the samples comprised predominantly White students.

${ }^{4}$ The mass-testing booklet contained a number of additional measures to be used by other researchers. A complete list of the items from all our individual difference measures can be obtained from the first author.

${ }^{5}$ For example, our measure included most of the items from Tougas et al.'s (1995) Neo-Sexism Scale, with the exception of three items that we thought might have content overlap with our dependent measure or other relevant constructs. These items were "Due to social pressures, firms frequently have to hire under-qualified women," "I consider the present employment system to be unfair to women," and "Discrimination against women in the labor force is no longer a problem in Canada."

${ }^{6}$ Note that the Belief in Merit Scale assesses individuals' endorsement of, or preference for, distributing outcomes on the basis of merit. It does not assess whether people believe that outcomes are in fact presently being distributed in this way.

${ }^{7}$ All studies reported in this article were conducted by a White male experimenter.
} 
promotion decisions even in situations where a target-group member is relatively less qualified than a non-target-group member. Thus, the program violated the traditional principle of meritocracy in the distribution of outcomes. Specifically, participants read the following:

When considering employees for hiring and promotion, a new procedure is used. A minimum qualification level for each position has been set. The most qualified applicant above this level receives the available position unless there are any target-group members (women, visible minorities, or physically challenged employees) above the minimum qualification level. In this case, the target-group applicant is selected before a potentially better qualified non-targetgroup employee.

Equal treatment program. In this condition, participants read about a program that was not preferential in that it offered benefits to all employees, although target-group members might benefit more due to their special needs. Thus, the program did not violate the principle of meritocracy. Specifically, participants read the following:

Unlike many affirmative action programs, this program does not involve preferential hiring or promotion. Instead, the program helps target groups by providing three new policies that all employees may take advantage of. First, employees are provided with a generous maternity/paternity leave program, flexible hours, and affordable day care to help them overcome difficulties associated with caring for children. Second, the organization has implemented a mentorship program to match inexperienced employees with more accomplished members of the corporation. Third, the company provides and pays for extra training and development courses.

\section{Measures}

Respondents' attitudes toward the program were assessed with the following question, rated on a 7-point scale (with endpoints labeled extremely unfavorable and extremely favorable): "How favorable do you feel about the Haines affirmative action program?" Scores were recoded such that higher numbers in the data analyses reflect greater opposition.

To check the success of the manipulation, participants responded (on a 7-point scale) to the question "Under the Haines program, what is the likelihood that a less qualified target-group member would be hired or promoted over a more qualified non-target-group member?"' This manipulation-check item came after the primary dependent measure but was separated from it by several items, not discussed here, used to assess participants' perceptions of the beneficiary. (Due to minor changes in the methodology of Study 2 to follow, we have data on perceptions of the beneficiary only in Study 1 . Given that these questions were not of primary interest for the present purposes, we do not discuss them here.)

\section{Results}

\section{Treatment of the Data: Overview}

We used both analysis of variance (ANOVA) and multiple regression procedures to analyze the data. For analyses involving only the categorical AA program variable, we used ANOVA to examine group differences. For analyses involving the continuous predictors (i.e., BIM and sexism), we used multiple regression rather than ANOVA to avoid artificial dichotomization of the predictors. Following procedures recommended elsewhere (e.g., Aiken \& West, 1991), the program was dummy coded in the regression analyses ( 0 or 1 , signifying membership in the
Table 1

Means, Standard Deviations, and Intercorrelations Among Predictors in Study 1

\begin{tabular}{lccccc}
\hline & & & \multicolumn{2}{c}{ Predictor } \\
\cline { 5 - 6 } Predictor & $M$ & $S D$ & & BIM & Sexism \\
\hline BIM & 3.90 & 0.38 & $(.62)$ & - \\
Sexism & 2.33 & 0.63 & $-.45^{* * *}$ & $(.83)$ \\
\hline
\end{tabular}

Note. Numbers in parentheses are Cronbach's alpha estimates of internal consistency. BIM = belief in merit. Higher scores on the predictors (1-5) reflect more of the construct. $N=53$ (because of missing data). $* * * p<.001$.

ET and PT programs, respectively ) and scores on all continuous predictors were centered. All terms hypothesized to have a significant effect were then entered simultaneously in the regression analyses. Given the difficulty in detecting moderation effects (e.g., Stone, 1988), we tested only the two first-order interactions for which we had a priori predictions (i.e., Sexism $\times$ Program; BIM $\times$ Program), as well as the lower-order effects of program, sexism, and BIM.

\section{Predictor Characteristics}

The means, standard deviations, reliabilities, and intercorrelations of the predictors are presented in Table 1. As can be seen, BIM and sexism were moderately negatively correlated, $r(53)$ $=-.45, p<.001$. Although the magnitude of the correlation was higher than we had expected (i.e., based on our scale construction efforts and preliminary data; see Davey, 1995), it is interesting to note the direction. Those with stronger sexist beliefs held weaker beliefs in merit. Thus, it is less likely that the effects of a strong belief in merit are due instead to prejudicerelated constructs (e.g., conservatism, right-wing authoritarianism, social dominance orientation). ${ }^{8}$

\section{Manipulation Check: Perceptions of Merit Violation}

A two-group one-way ANOVA confirmed the success of our manipulation. Specifically, participants in the PT (vs. ET) program reported that there was a significantly greater likelihood that a less qualified target-group member would be promoted over a more qualified non-target-group member $(M \mathrm{~s}=5.60$ vs. $3.58 ; S D \mathrm{~s}=1.35$ vs. 1.52 , respectively $), F(1,54)=26.84, p$ $<.001$.

We followed up the ANOVA with a regression analysis to assess potential differences on the manipulation check as a function of our individual difference predictors. The regression of perceptions of merit violation on program, BIM, sexism, and the two predicted interactions revealed only a significant effect

\footnotetext{
${ }^{8}$ Overall, the scale reliabilities and pattern of intercorrelations were the same in the larger mass-testing sample in Study 1. It is notable, however, that the magnitude of the correlation between belief in merit and sexism was reduced, $r(214)=-.34, p<.001$.
} 
of the program vector, $\beta=.55, p<.001$, paralleling the main effect noted earlier.

\section{Attitudes Toward the Two AA Programs}

To test our first hypothesis that attitudes would be more negative in the PT than the ET program, we conducted a two-group one-way ANOVA. As expected, we found a main effect of program, such that people in the PT program reported more opposition $(M=4.60, S D=1.80)$ than did people in the ET program $(M=2.52, S D=1.46), F(1,52)=23.88, p<.001 .^{10}$

\section{Attitudes as a Function of Individual Differences and Type of Program}

We conducted a regression analysis to test our hypotheses that the effects of the predictors on attitudes would depend on program type. The results are presented in Table 2.

Specifically, as shown in Table 2, we regressed attitudes on sexism, BIM, program, and the two predicted two-way interactions: Sexism $\times$ Program and BIM $\times$ Program. Identical to the ANOVA result presented earlier, the regression coefficient for the program vector was significant and positive, $\beta=.52, p<$ .001 . Neither the coefficient for sexism nor the Sexism $\times$ Program interaction was significant, $\beta \mathrm{s}=.06$ and .10 , respectively. The coefficient for BIM was marginally significant, $\beta=-.39$, $p=.06$. As expected, the effect for BIM was qualified by a BIM $\times$ Program interaction, $\beta=.71, p<.001$.

Figure 1 illustrates the BIM $\times$ Program interaction. As can be seen, the slope of the regression line is positive in the PT program, whereas it is negative in the ET program. In other words, in the PT program, higher scores on BIM were associated with greater opposition; in contrast, in the ET program, higher scores on BIM were associated with less opposition.

Together, program, sexism, BIM, and the hypothesized interactions accounted for $46 \%$ of the variance in attitudes toward AA (adjusted $R^{2}=.41$, correcting for relative error as recommend by Cattin, 1980).

\section{Discussion}

As expected, participants who evaluated an ET AA program were, in general, less opposed than those who evaluated a PT

Table 2

Standardized and Unstandardized Coefficients for the Regression of Opposition on the Predictors in Study 1

\begin{tabular}{lrcc}
\hline \multicolumn{1}{c}{ Predictor } & $B$ & $S E B$ & $\beta$ \\
\hline AA Program (A) & 2.00 & 0.41 & $.52^{* * *}$ \\
BIM (B) & -0.15 & 0.08 & $-.39 \dagger \dagger$ \\
Sexism (S) & 0.01 & 0.04 & .06 \\
B X A & 0.34 & 0.10 & $.71^{* * *}$ \\
S X A & 0.04 & 0.06 & .10 \\
Constant & 2.53 & 0.27 & - \\
\hline
\end{tabular}

Note. $R^{2}=.46$, adjusted $R^{2}=.41 . \mathrm{AA}=$ affirmative action; $\mathrm{BIM}=$ belief in merit. $N=53$ (because of missing data).

$\dagger \dagger p=.06$ (marginally significant). ${ }^{* * *} p<.001$.
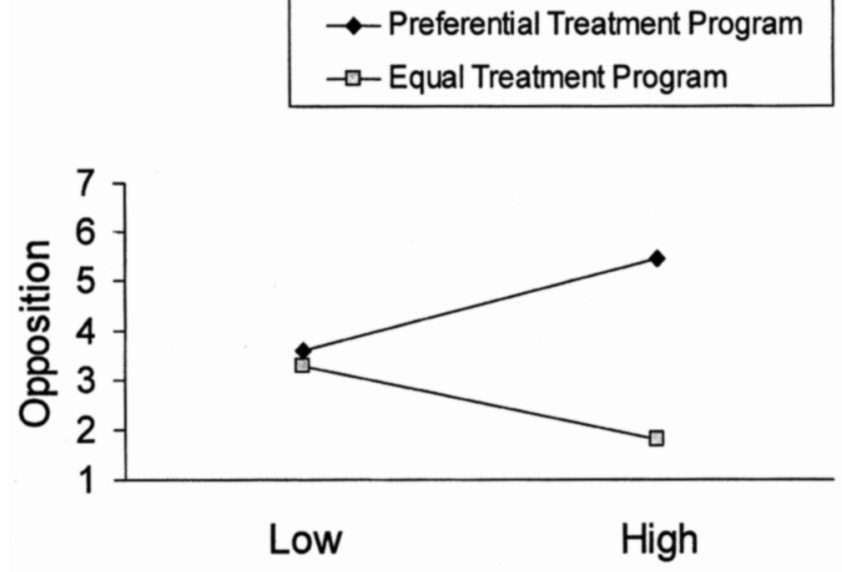

Belief in merit

Figure 1. The Belief in Merit (BIM) $\times$ Program interaction on opposition in Study 1. The graph depicts the relation between participants' scores on BIM (low and high) and opposition as a function of program. On BIM, low = two standard deviations below the mean, centered at zero; high $=$ two standard deviations above the mean. $N=53$.

program. Thus, consistent with past research, we found that the type of AA program influenced attitudes.

Furthermore, individual differences in justice beliefs were relevant to predicting attitudes toward $\mathrm{AA}$; however, in line with our hypothesis of justice as a cause, the relation between people's justice beliefs and their attitudes was contingent on the type of program-people who strongly believe in distributing outcomes on the basis of merit were significantly more opposed (relative to those who do not) but only in the case of the PT program. In fact, these same type of people (those with high BIM) were less opposed to the ET program than were their low scoring counterparts. Although the latter finding was not

\footnotetext{
${ }^{9}$ As recommended by Cohen and Cohen (1983), we present standardized regression coefficients (i.e., betas) in the text, for two reasons: (a) Not all measures were on the same scale, and (b) in Study 2 (to follow), we were interested in making relative comparisons in the magnitude among the coefficients. Both the unstandardized regression coefficients (Bs) and the betas are, nevertheless, presented in the relevant tables.

${ }^{10}$ We conducted analyses in all studies to assess potential gender differences in attitudes toward the programs. In Study 1, a 2 (Program) $\times 2$ (Gender) ANOVA revealed a significant interaction between these factors, $F(1,52)=4.98, p<.05$. Men were more opposed to the ET program than were women $(M \mathrm{~s}=3.06$ vs. $1.77 ; S D \mathrm{~s}=1.55$ and 0.93 , respectively), $t(29)=2.66, p<.05$. Women were slightly more opposed to the preferential treatment program than were men $(M s=5.00$ vs. $4.38 ; S D \mathrm{~s}=2.18$ and 1.59 , respectively), however, this difference was not significant, $t(23)=-0.83, p>.10$. The Gender $\times$ Program interaction was not significant in the replication of Study 1 nor in Study 2 (to follow). In Study 3, we found that gender related to opposition to a "typical" AA program (men were more opposed than were women), but gender did not moderate the primary results. Given that we had no a priori reason to predict that our results would differ by gender (nor did our data suggest otherwise), we do not discuss gender in detail in this article (but see Footnote 18).
} 
hypothesized a priori, it is not inconsistent with the notion of justice concerns as a determinant of attitudes. Thus, when evaluating a program that did not violate merit, people who believe strongly in the merit principle were in fact more favorable toward it than were people who do not. Unexpectedly, whereas we found support for our hypothesis regarding justice beliefs, prejudice - in the form of sexism-failed to have a unique influence on attitudes in Study 1.

To assess the stability of the justice findings and to improve our measurement of prejudice, we conducted a replication experiment $(N=85)$ in which we broadened our measurement of prejudice to include both sexism and racism; thus, we included a nine-item version of McConahay's, 1986, Modern Racism Scale. " The results of the replication experiment were virtually identical to those reported earlier: (a) Participants were again more opposed overall to the PT versus ET program $(M \mathrm{~s}=4.56$ vs 2.17$), F(1,83)=50.42, p<.001$; (b) individuals' BIM affected attitudes differentially as a function of program, in the same manner as before $(\beta=.24, p=.05)$; and (c) prejudice again failed to have a unique effect on attitudes. It is noteworthy that in a regression analysis to examine the effect of the individual difference variables on the manipulation check, prejudice did have a significant effect. That is, high prejudiced people perceived a greater likelihood of merit violation overall than did less prejudiced people ( $\beta=.48, p<.01)$; moreover, a significant Prejudice $\times$ Program interaction $(\beta=-.40, p<.05)$ indicated that this effect of prejudice was significant only in the ET program. Thus, although the effect of prejudice on attitudes in the ET program was not significant in the replication, prejudice influenced how participants construed the program in a manner that was consistent with our predictions.

On the surface, the nonsignificant link between prejudice and attitudes in Study 1 seems contradictory to past research; there are, however, several considerations that make it difficult to draw comparisons. For example, typically the characteristics of the AA program have not been defined explicitly in past research. Moreover, many past studies have not controlled for the possible confounding effects of justice beliefs in the relation between prejudice and attitudes. Finally, whereas we obtained the predictors and criterion in different settings and at different points in time (one month apart), concurrent measurement is more typical. On the basis of such methodological features, it is plausible that we put the prejudice-to-attitudes link to a particularly conservative test.

Encouraged by our initial justice findings, we designed a second experiment to replicate and extend them to procedural justice-based opposition. As well, we sought to strengthen our test of the role of prejudice by modifying several methodological features. In particular, with the wisdom of hindsight, it seemed plausible that we did not adequately prime prejudice in our stimulus materials. For example, we realized that we had inadvertently identified women and minority group members as potential beneficiaries in the PT program but not in the ET program (where we indeed expected the effect). Accordingly, we altered the stimulus materials in Study 2 to prime prejudice more strongly (details to follow).

\section{Study 2}

As noted earlier, we reasoned that people's BIM should predict opposition to the PT program because it violates one's sense of justice-in particular, the equity rule, or the merit principle, of distributive justice. It could be argued, however, that the PT program also violates the consistency principle of procedural justice (e.g., Lea, 1995; Leventhal, 1980). In brief, the consistency principle holds that, in making decisions about the allocation of outcomes, all people should be treated the same procedurally. Indeed, in violating the merit principle, the PT program necessarily violates consistency.

Consequently, we extended our justice findings by conducting a second experiment in which we added a third AA programone which violates the consistency principle of procedural justice but not the merit principle of distributive justice. The specific program we described was one in which a target-group member could be selected for hiring or promotion over a nontarget-group member only in conditions where the candidates are equally qualified. Thus, this program (like the PT program in Study 1 and its replication) involves inconsistent treatment of the two candidates (i.e., the selection process systematically favors target-group members over non-target-group members); however, the merit principle is not violated, because the candidates are equally qualified (i.e., in no case would a less qualified target person be promoted over a more qualified nontarget person).

The preceding program, which we refer to as a "Tie" program, falls in between our ET and PT programs on the continuum of possible AA strategies noted in the introduction. Given this, and on the basis of past research findings, we expected that the overall level of opposition to the Tie program would fall in between the levels of opposition to the other programs.

Furthermore, if it were true that the Tie AA program violates the procedural justice principle of consistency, then, applying the same logic as that outlined previously for the PT program, we would expect that opposition to the Tie program would be predicted by individual differences in people's endorsement of the consistency principle. Therefore, we created an individual difference measure to assess people's belief in the procedural justice rule of consistency, and we used it as a predictor in Study 2 along with the BIM and prejudice measures.

Paralleling our original prediction that belief in the merit principle would predict opposition to the PT program but not the ET program, we predicted a Belief in Consistency (BIC) $\times$ Program interaction, such that BIC would predict opposition to the Tie program but not the others. That is, the difference between people with high and low BIC should be smaller in the ET program, where consistency is not violated. Similarly, although the PT program does violate consistency, the difference between those scoring high and low on BIC should be smaller, because merit is also violated. In other words, BIC might not be sufficient to influence attitudes toward the PT program (i.e., both those scoring high and low will generally be opposed), given that the merit principle is also violated.

Although we hypothesized that BIC would predict attitudes toward the Tie program, several justice researchers have recognized that inconsistent treatment (such as our Tie program)

\footnotetext{
${ }^{11}$ The items were adapted for a Canadian context, by Dale Griffin, by referring to visible minorities versus Blacks. We created a prejudice composite by first standardizing scores on each of the sexism and modern racism scales, then averaging those scores.
} 
might not always be objectionable. Indeed, Crosby and her colleagues (Crosby, 1994; Smith Winkelman \& Crosby, 1994) have suggested that, in the context of AA, inconsistent treatment might be judged as fair by people who believe that target-group members face discrimination. In other words, people might be less opposed to inconsistent treatment - and, hence, the Tie program - the more they perceive discrimination.

Thus, in addition to the prejudice and justice measures (i.e., BIM and BIC), we included a measure in Study 2 to assess perceptions of workplace discrimination. On the basis of Crosby's reasoning, and in line with our general notion that the determinants of opposition differ depending on program characteristics, we expected that perceived discrimination might influence attitudes toward the Tie program. Perhaps more interesting, it also seemed possible that perceptions of discrimination might moderate our hypothesized effect of BIC on attitudes toward the Tie program. In other words, whereas in general the higher people's belief in consistent treatment, the more they will oppose inconsistent treatment, this effect might be "overridden" by perceptions of workplace discrimination. In contrast to the Tie AA program, we expected that perceptions of workplace discrimination might not be sufficient to affect opposition to the PT program, which violates the merit principle of distributive justice. Similarly, perceptions of discrimination might not relate to attitudes toward the ET program. That is, all else (e.g., prejudice levels) being equal, participants should endorse the ET program regardless of their perceptions of discrimination, because the program can benefit all employees.

Finally, to strengthen our test of prejudice effects, we altered the stimulus materials in Study 2 to prime both race and sex. Compared with Study 1, then, in Study 2, we used a broader measurement of prejudice-both racism and sexism-and, in parallel, our experimental materials made both race and sex salient.

\section{Mediation of the Effects Through Construal}

We found it theoretically interesting that, despite our efforts to experimentally manipulate the specifics of the AA program being evaluated (as either involving preferential treatment or not), participants' prejudice level in the replication of Study 1 still affected how they construed the object of evaluation. Consequently, in an effort to understand the process underlying the effects of the individual difference variables on attitudes, we examined whether they are mediated, at least in part, by participants' construal of the program as merit or consistency violating.

According to Fishbein and Ajzen (1975), attitudes are a function of the evaluative implications of the beliefs we hold about the attitude object. If we assume that our construal measures (i.e., perceptions of merit and consistency violation) represent participants' beliefs about the attitude objects (the AA programs being judged), then mediation analyses could suggest whether the link between an individual difference variable and opposition to a specific AA program is influenced (a) by different beliefs that people scoring high and low on the individual difference variable have about the attitude object or (b) by different evaluations that people scoring high and low on the individual difference variable have of the beliefs.
Put differently, to the extent that the relation between an individual difference variable (e.g., prejudice) and opposition (e.g., to the ET program) is fully mediated by construal, this would be consistent with the idea that the differing attitudes of participants scoring high and low on the individual difference variable are a result of differing beliefs about the attitude object. In contrast, no mediation would be consistent with the notion that the differing attitudes of participants scoring high and low on the individual difference variable are due to differing evaluations of the characteristics attributed to the attitude object. Restated in Asch's (1948) classic terms, no mediation would be consistent with the interpretation that people scoring high and low on an individual difference variable have different judgments of the object, whereas complete mediation would be consistent with the interpretation that people who score high and low on an individual difference variable have different objects of judgment.

More concretely, in line with the idea that prejudiced people might rationalize their opposition in the name of justice, we explored the idea that they oppose the ET program (more than less prejudiced people) because of their tendency to construe the ET program as violating justice principles (e.g., consistency or merit). Moreover, on the basis of past theorizing about the fairness of inconsistent treatment (e.g., Crosby, 1994), we tested the idea that the moderating effect of discrimination in the relation between BIC and opposition to the Tie program is mediated, at least in part, by perceptions of consistency violation. Presumably, if individuals believe that target-group members face discrimination, and hence that inequality exists, they would be less inclined to perceive the Tie program as consistency violating; in turn, their justice beliefs (i.e., BIC) should predict opposition to the Tie program less strongly.

\section{Method}

\section{Participants and Design}

Two hundred twenty-three students completed the mass-testing booklet; of these, 86 students ( 52 women, 34 men) participated in Study 2. Given the increased number of predictors, we used a within-subjects design to increase our statistical power. Thus, participants, pretested on sexism, modern racism, BIM, BIC, and perceived discrimination, were assigned to each of three experimental conditions, counterbalanced for order: type of AA program (ET, Tie, and PT).

\section{Procedure}

We made two primary changes to the procedure. First, we made both race and sex salient in our materials by (a) replacing our previous picture - of a White woman - with one including three people: a Black woman, an Asian woman, and a Hispanic man; and (b) adding a sentence at the start of each program description in which we stated explicitly that the program aimed to assist women and minority groups.

Second, participants were told that the company was requesting their input on each of three different AA programs that they were considering for implementation. Ostensibly, each of the programs had already been implemented by other companies ( simply labeled Corporation A, B, and C). The stimulus materials were presented in booklet form with the general background information about the purpose of the survey on the first page; on each of the three following pages was a description of one of the programs (at the top of the page) followed by the dependent measures (which referred to the specific program). The order in which 
the three programs were evaluated was counterbalanced, with participants receiving one of six possible combinations (e.g., ET, Tie, PT; ET, PT, Tie; and so forth).

In the Tie AA manipulation, participants read about an AA program that violates the consistency principle of procedural justice by using group membership in decision making, but does not violate the merit principle of distributive justice because a less qualified target-group member is never hired or promoted before a more qualified non-targetgroup member. Specifically, participants read the following:

Corporation [A, B, or C's, depending on order] affirmative action program is aimed to assist women, minority groups, and the physically challenged. This program has altered Corporation [A, B, or $\mathrm{C}$ 's] hiring and promotion policy. If there is an instance in which there are equally qualified candidates competing for a position, preference is given to target-group members. This policy gives women, visible minorities, and the physically challenged an advantage; however, it does not mean that a target-group member with relatively weaker qualifications would ever be hired or promoted before a more qualified non-target-group member. Rather, consideration is given to group membership only when candidates for a position are equally qualified.

The first line was also added to the ET and PT programs used previously.

\section{Measures}

We added two predictors in mass testing: a 20 -item measure to assess participants' belief that, to be fair, people should be treated the same procedurally, regardless of the outcome and an eight-item measure to assess perceptions of discrimination in the workplace (Son Hing, 1997). Two example items (rated on a 5-point scale with endpoints labeled extremely unfair and extremely fair) from the BIC are "To treat all customers the same, airlines ought to charge all people the same price per seat in economy class. This would mean that overweight people would be forced to pay for either two seats or one larger first class seat" (positively keyed), and "To equalize the affordability of entrance, many places (e.g., movie theatres) ought to offer cheaper admission prices for groups with low fixed incomes like seniors and students" (negatively keyed). Items on the BIC scale were written to tap one's preference for consistent treatment in several domains, such as business, school, and sports. Two example items from the discrimination scale (rated on a 5point disagree-agree scale) are "Currently, women are disadvantaged by negative gender stereotypes regarding their ability to perform work" (positively keyed), and "Historically, visible minorities were not disadvantaged in their chances of being hired or promoted because of inherent barriers in the workplace" (negatively keyed). Items on the discrimination scale tapped perceptions of both past and present discrimination, discrimination against women and visible minorities, as well as systemic- and individual-level discrimination. ${ }^{12}$

We added a dependent measure in the experimental materials to assess perceptions of the likelihood of consistency violation. Specifically, participants were asked, "Under Corporation [A, B, or C's] program, what is the likelihood that all employees will be evaluated by the same standards in hiring and promotion?' (7-point scale with endpoints labeled extremely unlikely and extremely likely).

Finally, to improve the measurement of our attitude dependent variable, we added two additional questions (rated on 7-point scales): "Overall, what is your opinion of Corporation [A, B, or C]?' (endpoints were labeled extremely unfavorable and extremely favorable) and "How likely is it that you would recommend that Cochrane Industries implement Corporation [A, B, or C's] program?' (endpoints were labeled extremely unlikely and extremely likely). The three attitude items were highly intercorrelated within each AA program (i.e., the Cronbach's alpha in the ET, Tie, and PT programs were as follows: $.85, .95$,
$.84)$; thus, a composite was formed by averaging the three items. Items were recoded such that higher scores in the data analyses reflect more consistency violation and more opposition.

\section{Results}

\section{Predictor Characteristics}

The means, standard deviations, reliabilities, and intercorrelations of the predictors are presented in Table 3. As can be seen, scores on the BIM and BIC were not correlated, confirming their independence. Moreover, the BIM showed good discriminant validity in that it did not correlate significantly with the other predictors. The discriminant validity of the BIC was also generally good, although there was a significant positive correlation between BIC and modern racism, $r(83)=.36, p<.01$, and a significant negative correlation with perceived discrimination, $r(83)=-.21, p<.05$. In other words, people who are more racist also tend to believe that everyone should be treated the same procedurally, regardless of the outcome. In contrast, the more people perceive discrimination, the less strongly they endorse the consistency principle. Although these correlations are significant, they are not of sufficient magnitude to suggest that the BIC is redundant with the other constructs.

A composite of prejudice comprising sexism and modern racism was formed by averaging respondents' standardized scores (e.g., Pedhauzur, 1982), $r(83)=.33, p<.01$. There was a sizable negative correlation between scores on the prejudice composite and perceptions of discrimination, $r(83)=-.54, p$ $<.001$, such that people who scored higher on prejudice perceived less discrimination. ${ }^{13}$

\section{Preliminary Analysis: Effect of Order on Attitudes}

A 3 (program) $\times 6$ (order) split-plot ANOVA (repeated measures on program, between subjects on order) was conducted to determine whether order had any effect on attitudes. The analysis revealed a main effect of order, $F(5,80)=3.58, p<$ .01 , and a marginally significant interaction between order and program, $F(10,160)=1.81, p=.06$.

Post hoc tests of means of the interaction revealed the following: There were no significant differences among the six orders within either the ET program (where mean attitudes ranged from 1.74 to 2.56 ) or the PT program (where mean attitudes ranged from 4.97 to 5.75 ). Only in the Tie program did attitudes differ significantly according to order. Nevertheless, even within the Tie program, there was only one significant difference

\footnotetext{
${ }^{12}$ Preliminary psychometric analyses on the belief in consistency (BIC) and perceived discrimination scales were conducted using the data from one half of the mass-testing participants who did not participate in the study. These analyses resulted in our dropping four items from an initial version of the BIC. Such items either had a low item-total correlation or correlated more highly with another scale than with their own scale.

${ }^{13}$ In the larger mass-testing sample, the pattern of internal consistencies for the predictors and the intercorrelations was very similar, although BIC correlated less strongly with modern racism, $r(231)=.24, p<$ .001 , and, consequently, with the prejudice composite, $r(225)=.18, p$ $<.01$.
} 
Table 3

Means, Standard Deviations, and Intercorrelations Among Predictors in Study 2

\begin{tabular}{lccccccc}
\hline & & & \multicolumn{5}{c}{ Predictor } \\
\cline { 4 - 8 } Predictor & $M$ & $S D$ & BIM & BIC & Discrim & MR & Sexism \\
\hline BIM & 3.96 & 0.39 & $(.69)$ & - & - & - & - \\
BIC & 2.63 & 0.35 & .07 & $(.66)$ & - & - & - \\
Discrim & 3.83 & 0.52 & -.06 & $-.21^{*}$ & $(.72)$ & - & - \\
MR & 3.60 & 1.37 & .16 & $.36^{* *}$ & $-.36^{* * *}$ & $(.82)$ & - \\
Sexism & 2.15 & 0.55 & -.14 & .13 & $-.52^{* * *}$ & $.33^{* *}$ & $(.82)$ \\
Prejudice & 0.00 & 0.82 & .01 & $.30^{* *}$ & $-.54^{* * *}$ & $.82^{* * *}$ & $.81^{* * *}$ \\
\hline
\end{tabular}

Note. Numbers in parentheses are Cronbach's alpha estimates of internal consistency. BIM = belief in merit; $\mathrm{BIC}=$ belief in consistency; discrim = perceptions of workplace discrimination; $\mathrm{MR}=$ modern racism. Higher scores on the variables reflect more of the construct. Scores on variables range as follows: BIM, BIC, discrim, and sexism: 1-5; MR: 1-9; prejudice: -2 to 2 . The prejudice composite was created by first standardizing scores on each of the sexism and MR scales, then averaging scores, thus, $M=0$, and the traditional Cronbach's alpha estimate of reliability is not appropriate. $N=83$ (because of missing data). $* p<.05 . \quad * * p<.01 . \quad * * * p<.001$.

among the six orders. Specifically, participants reported more opposition to the Tie program when they received the following order of program: ET, Tie, PT ( $M=4.44)$, as compared with when the order was Tie, PT, ET ( $M=2.42)$. The mean attitudes for the remaining orders fell between these two values, and none differed significantly from any other.

Thus, opposition to the Tie program was influenced to some degree by the order in which participants were exposed to the three programs. However, given that order had a significant effect on attitudes toward the Tie in only two of six orders (thereby involving only one third of the participants), it is unlikely that the effects of the predictors on attitudes within this condition (to follow) could be accounted for by order. Nonetheless, we included order as a covariate in subsequent analyses conducted within the Tie condition.

\section{Manipulation Check: Perceptions of Merit and Consistency Violation by Program}

Repeated measures ANOVA by program revealed a significant effect on perceptions of merit violation, $F(2,170)=79.52, p$

Table 4

Mean Ratings on Dependent Variables in Study 2 as a Function of AA Program

\begin{tabular}{lccr}
\hline & \multicolumn{3}{c}{ AA program } \\
\cline { 2 - 4 } Dependent variable & ET & Tie & PT \\
\hline \multirow{2}{*}{ Merit violation } & $2.99_{\mathrm{a}}$ & $3.04_{\mathrm{a}}$ & $5.80_{\mathrm{b}}$ \\
& $(1.49)$ & $(1.89)$ & $(1.73)$ \\
Consistency violation & $3.14_{\mathrm{a}}$ & $3.94_{\mathrm{b}}$ & $5.77_{\mathrm{c}}$ \\
& $(1.65)$ & $(1.71)$ & $(1.28)$ \\
Opposition & $2.08_{\mathrm{a}}$ & $3.36_{\mathrm{b}}$ & $5.48_{\mathrm{c}}$ \\
& $(0.81)$ & $(1.42)$ & $(1.05)$ \\
\hline
\end{tabular}

Note. $\mathrm{AA}=$ affirmative action; $\mathrm{ET}=$ equal treatment; $\mathrm{PT}=$ preferential treatment. Standard deviations are in parentheses. Higher scores (17) reflect more of the construct. Groups not sharing a subscript differ significantly at $p<.05$ (Kirk, 1982). $N=86$.
$<.001$, as well as consistency violation, $F(2,170)=69.17, p$ $<.001$.

As shown in Table 4, on perceptions of merit violation, ratings were significantly higher, as expected, in the PT program ( $M$ $=5.80)$, as compared with both the Tie $(M=3.04)$ and ET programs $(M=2.99) ; t(85)=10.39, p<.001$, for the comparison between the PT and Tie programs.

Also as expected, participants perceived significantly more consistency violation in both the PT $(M=5.77)$ and Tie programs $(M=3.94)$, as compared with the ET program $(M=$ $3.14), t(85)=11.84, p<.001$ and $t(85)=3.10, p<.01$, respectively. The difference between the PT and Tie programs was, however, also significant, $t(85)=9.01, p<.001$.

In a subsequent section, we present regression analyses that assess the role of merit and consistency violation as mediators in the links between individual differences and attitudes. In the interest of brevity, we do not report the repeated-measures analysis regressing the construal measures on all of the individual difference predictors. To do so would have resulted in unwieldy regression models, which were not of primary interest. ${ }^{14}$

\section{Attitudes Toward the Three AA Programs}

The ANOVA of attitudes by program revealed a significant main effect, $F(2,170)=226.85, p<.001$. Table 4 shows mean attitudes as a function of program. As expected, opposition was greatest in the PT program $(M=5.48)$ and least in the ET program $(M=2.08)$, and opposition to the Tie program fell between these values $(M=3.36)$. As shown in Table 4 , each

\footnotetext{
${ }^{14}$ Specifically, we would have had to enter seven terms to represent main effects (BIM, BIC, prejudice, perceived discrimination, two program vectors to represent membership in one of the three programs, a vector to represent participants, or the within-cell yariability, see Pedhauzur, 1982), and eight terms to represent only the first-order hypothesized interactions (i.e., BIM $\times$ Program Vector 1 , BIM $\times$ Program Vector 2, and so forth, for the remaining three individual difference predictors. Thus, the most simple regression model would have necessitated entering 15 predictors.
} 
mean differed statistically from the others. (For the comparison of PT and Tie programs, $t(85)=12.31, p<.001$; for the comparison of Tie and ET programs, $t(85)=7.75, p<.001$.)

It is also noteworthy that, overall, participants' attitudes toward each program were relatively independent. That is, the intercorrelations among attitudes toward the three programs were statistically nonsignificant $(p>.10), r s(83)=.11,-.10$, and .11, between the ET and Tie, ET and PT, and Tie and PT programs, respectively. The fact that attitudes toward the three programs were independent of one another is consistent with the idea that there are different determinants of attitudes toward $\mathrm{AA}$, and, thus, the stage was set to test our hypotheses.

\section{Attitudes as a Function of Individual Differences and Type of Program}

To test our hypotheses about the differential roles of prejudice, BIM, BIC, and perceptions of discrimination in predicting attitudes as a function of AA program, we regressed attitudes on the four individual difference predictors within each program. The standardized regression coefficients (betas) are presented in Table 5.

As can be seen in Table 5, in the ET program, only the regression coefficient for prejudice was significant $(\beta=.34, p$ $<.05$ ). Thus, in Study 2 , the more prejudiced the respondent, the more he or she opposed the ET program. Consistent with the results of Study 1 and the replication study, BIM significantly predicted attitudes in the PT program $(\beta=.35, p<.01)$. Thus, the more strongly participants believe in the merit principle, the more they opposed the PT program. Finally, in the Tie program, the coefficient for BIC $(\beta=.18, p=.09)$ was marginally significant. Thus, in general, the more participants believe in consistent treatment, the more they opposed the Tie program. The coefficient for the first-order effect of perceived discrimination was also marginally significant $(\beta=-.20, p=.09)$. In line with theorizing presented earlier, the more workplace discrimination perceived by participants, the less they opposed the Tie program. ${ }^{15}$

It is noteworthy that, in a follow-up regression analysis in the Tie program where we added the BIC $\times$ Perceived Discrimination moderation term, we found a marginally significant effect $(\beta=-.17, p=.09)$. Although the interaction did not attain

Table 5

Within-Cell Standardized Regression Coefficients (Betas) Predicting Opposition in Study 2

\begin{tabular}{lccc}
\hline & \multicolumn{3}{c}{ AA program } \\
\cline { 2 - 4 } Predictor & ET & Tie & PT \\
\hline Prejudice & $.34 *$ & .16 & .12 \\
BIM & -.01 & .05 & $.35^{* *}$ \\
BIC & -.06 & $.18 \dagger$ & -.03 \\
Discrim & .12 & $-.20 \dagger$ & .06 \\
\hline
\end{tabular}

Note. $\mathrm{AA}=$ affirmative action; $\mathrm{ET}=$ equal treatment; $\mathrm{PT}=$ preferential treatment; $\mathrm{BIM}=$ belief in merit; $\mathrm{BIC}=$ belief in consistency; discrim $=$ perceptions of workplace discrimination.

$* p<.05 . \quad{ }^{* *} p<.01 . \quad \dagger p=.09$ (marginally significant). $\neg$ Low Discrimination

$\rightarrow-$ High Discrimination

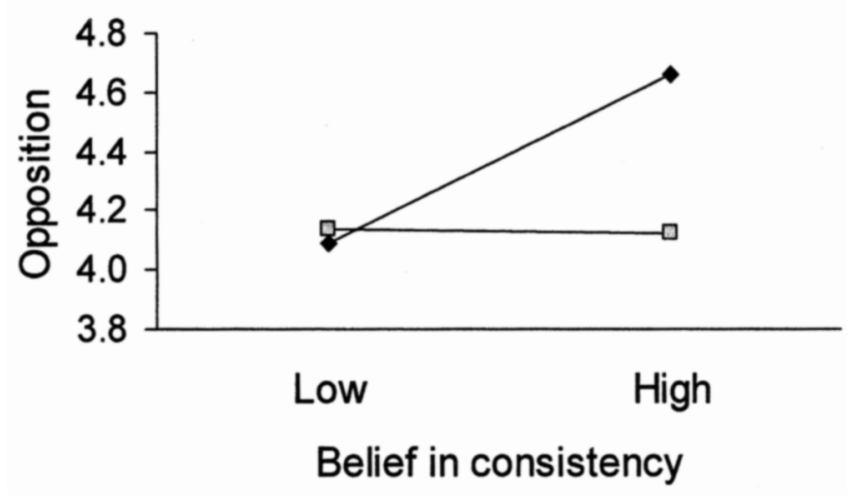

Figure 2. The moderating effect of perceptions of workplace discrimination in the relation between belief in consistency (BIC) and opposition to the Tie program in Study 2. The graph depicts the relation between participants' scores on BIC (low and high) and opposition to the Tie as a function of their perceptions of workplace discrimination (low and high). On both predictors, low $=$ two standard deviations below the mean, centered at zero; high $=$ two standard deviations above the mean. $N=83$.

the conventional level of statistical significance, we plotted the regression lines to examine the pattern. As can be seen in Figure 2 , the effect of BIC on opposition to the Tie was stronger among those who perceived less (vs. more) discrimination. ${ }^{16}$

\footnotetext{
${ }^{15}$ We conducted a series of more complex hierarchical regression analyses to confirm the significance of the primary Program $\times$ Individual difference interactions that are implied by the data presented in Table 5. More specifically, we conducted four analyses as follows: On a first step of each analysis, we entered a vector representing the subject or within-cell variability using criterion scaling, as outlined by Pedhauzer (1982). On a second step, we entered first-order terms (i.e., two dummy coded program vectors and the four individual difference predictors: prejudice, BIM, BIC, discrimination). On a third step, we entered the two terms representing a particular Program $\times$ Individual difference interaction (i.e., Program Vector $1 \times$ IV, Program Vector $2 \times I V$ ). Each analysis was identical, except for this last step in which case, in one analysis, we entered the terms to assess the Prejudice $\times$ Program interaction (Program Vector $1 \times$ Prejudice, Program Vector $2 \times$ Prejudice). In a second case, we entered the two terms to assess the BIM $\times$ Program interaction, and so forth. In all four analyses, the addition of the Program $X$ Individual difference interaction terms added significantly to the regression equation. Specifically, for the Prejudice $\times$ Program interaction: $\Delta R^{2}=.01, p<.05$; for BIM $\times$ Program, $\Delta R^{2}=.01, p<.05$; for BIC $\times$ Program, $\Delta R^{2}=.01, p<.05$; for Discrimination $\times$ Program, $\Delta R^{2}=.01, p<.001$. These analyses indicate that prejudice, BIM, BIC, and perceptions of discrimination each predict opposition differentially among the three programs, as revealed more simply in Table 5. (To conserve space, the complete regression models are not included here, because they were not of primary interest. They are available on request from the first author.)

${ }^{16}$ Note that the main effect for discrimination was no longer marginally significant when the interaction term was included in the regression equation.
} 


\section{Mediation of the Effects}

Following procedures outlined by others (e.g., Baron \& Kenny, 1986; Cohen \& Cohen, 1983), we conducted a series of regression analyses to explore whether the relations between the individual difference predictors and opposition to each of the AA programs (presented in Table 5) were mediated by participants' construal of the program as merit or consistency violating. The results of the path analyses are presented in Figure $3 .^{17}$

As shown in the top panel of Figure 3, the data are consistent with the notion that the link between prejudice and opposition to the ET program is mediated by participants' construal of the program as consistency violating. That is, whereas the total effect between prejudice and opposition was significant ( $\beta=$ $.22, p=.02$, given inside parentheses ), the effect is no longer
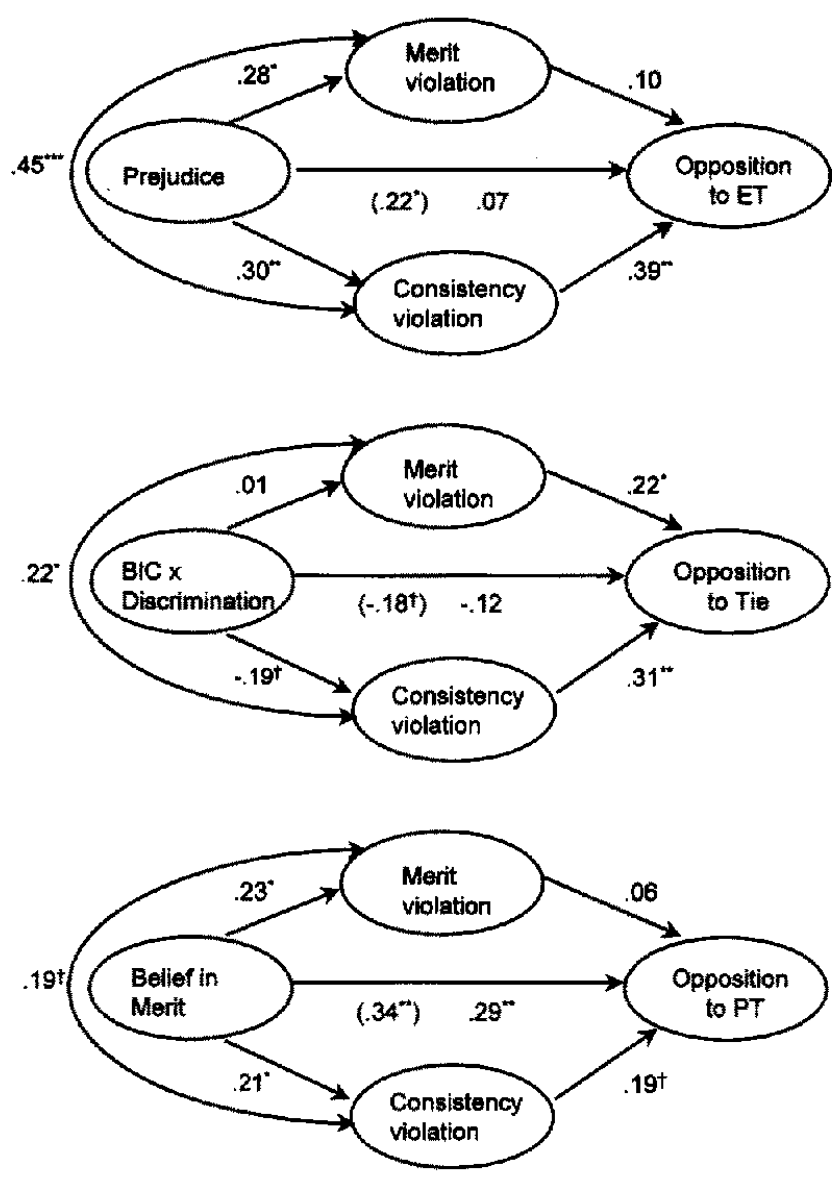

Figure 3. Path analyses in Study 2 depicting the mediating role of construal in (a) the link between prejudice and opposition to the equal treatment (ET) program (top panel); (b) the joint effect of belief in consistency (BIC) and perceived discrimination on opposition to the Tie program (middie panel); and (c) the link between belief in merit and opposition to the preferential treatment (PT) program (bottom panel). Numbers on paths are betas. The total effect between the predictor and criterion (i.e., before controlling construal) is given inside parentheses; the direct effect (i.e., after controlling construal) is given outside parentheses. ${ }^{*} p<.05 . \quad * * p<.01 . * * * p<.001 . \quad+p=.09$ (marginally significant). $N \mathrm{~s}=84,83$, and 86 , respectively, because of missing data. statistically significant when construal is controlled (beta for the direct effect $=.07, p>.10$, given outside parentheses). To pursue these data further, we tested the significance of the reduction between the indirect and direct effects (using Goodman's 1960 method). In line with mediation, the decrease was significant, $z=2.27, p=.02$. (Note that the nonsignificant path between perceptions of merit violation and opposition [.10] implicates consistency violation in particular as the mediator of the prejudice-to-opposition relation. Nevertheless, perceptions of merit and consistency violation were highly intercorrelated in the ET program, $r[85]=.50, p<.001$, which makes it difficult to disentangle the independent roles of merit vs. consistency violation as mediators.)

We conducted a similar analysis in the Tie program, to examine the pattern of data. More specifically, we explored the possibility that the moderating effect of perceptions of workplace discrimination in the relation between $\mathrm{BIC}$ and opposition to the Tie (i.e., BIC $\times$ Discrimination interaction effect) was mediated through construal. (In other words, we conducted a mediatedmoderation analysis; for details, see Baron \& Kenny, 1986.) As shown in the middle panel of Figure 3, the pattern is not strong, but it is in line with the idea of mediation through consistency violation. That is, the BIC $\times$ Discrimination interaction effect on opposition was slightly reduced when construal was controlled (beta for the total effect $=-.18, p=.09$; beta for the direct effect $=-.12, p>.10$; the decrease in effect size was marginally significant, $z=1.64, p=.10$ ). In summary, although the data are not as strong as in the ET program, the pattern is intriguing. The data are in line with the idea that the mitigating effect of perceptions of workplace discrimination in the relation between BIC and opposition to the Tie could be partially mediated by people's perception of the program as less consistency violating.

Finally, as shown in the bottom panel of Figure 3, there is little support for mediation in the PT program: First, the effect of BIM on opposition did not differ statistically before and after the construal variables were controlled $(\beta=.34, p<.01$ and $.29, p<.01$, respectively; $z=1.43, p>.10$ ). Second, the weak links between construal and opposition render mediation in the PT program less plausible.

\section{Discussion}

The findings of Study 2 replicate and extend our initial results. First, once again, we found that participants were least opposed to the ET and most opposed to the PT program; as expected, the level of opposition to the Tie fell between the ET and PT programs.

Second, opposition to each of the three AA programs was predicted by different individual difference variables (and consistent with this, opposition to any of the three programs was quite independent of opposition to the others ). More specifically, analyses to assess the unique contribution of prejudice and justice beliefs in predicting opposition toward the AA programs

\footnotetext{
${ }^{17}$ We examined possible mediation only for those individual differences found to predict attitudes in the regression analyses presented in Table 5 .
} 
revealed the following: (a) Opposition to the ET program was predicted uniquely by people's level of prejudice; (b) opposition to the PT program was predicted uniquely by BIM; and (c) opposition to the Tie program was predicted most strongly by BIC, and this was particularly true among people who perceive less (vs. more) workplace discrimination. Although, strictly speaking, the effects in the Tie program did not attain statistical significance, they were clearly approaching the conventional level, and the pattern of data is in line with our theoretical predictions.

The mediation analyses provide some preliminary insight into the process by which various individual differences might influence opposition. Following the logic outlined earlier, the fact that the effect of prejudice on opposition to the ET program was completely mediated by construal of the program as consistency violating is consistent with the idea that people high and low in prejudice have different beliefs about the ET program-that is, their differing attitudes about this program could be due to the fact that people high in prejudice systematically construe it as more consistency violating than do those low in prejudice. In contrast, the lack of strong evidence to suggest that the effect of BIM on opposition to the PT program was mediated by construal is consistent with the idea that people who do and do not strongly believe in the merit principle hold the same beliefs about the PT program, but they evaluate the violation of justice norms differently - that is, their differing attitudes toward this program could be due to the fact that those scoring high on BIM simply object more to violation of the merit principle than do those scoring lower.

Unlike in the PT program, there was some preliminary support for the mediating role of beliefs in the Tie program (although the effects were not as strong as in the ET program). Specifically, the pattern of the mediation analysis is consistent with the idea that the positive effect of BIC on opposition to the Tie program is lessened when people also perceived high (vs. low) discrimination, because those who perceive high discrimination construe the program as less consistency violating. In line with Crosby's (1994) theorizing, then, it is possible that perceptions of workplace discrimination could excuse or mitigate adverse reactions to a policy that violates the consistency principle of procedural justice among individuals who generally endorse it, as a result of a reduced tendency to perceive the policy as consistency violating. Given that our findings in the Tie program were not as strong as in the other programs, future research is necessary to pursue the present data.

\section{Study 3}

Whereas the results of Study 2 provided further support for the notion that justice-based opposition to AA can be genuine, we were also intrigued by mediation findings in the ET program. Given that, in the materials, we explicitly stated that the ET program did not involve preferential treatment (and therefore it did not violate consistency), the findings are consistent with the argument that prejudiced people might rationalize or internally justify their opposition to AA in the name of justice (Dovidio, 1996; Gaertner \& Dovidio, 1986; Murrell, Dietz-Uhler, Dovidio, Gaertner, \& Drout, 1994).

In view of our prejudice finding in Study 2, we conducted a third study to investigate how prejudice and justice beliefsBIM and BIC-relate to opposition to and construal of an undefined AA program. As noted earlier, typically AA is undefined in past research that shows links between prejudice and attitudes. Thus, on the basis of the past literature, we expected that respondents' prejudice level would predict opposition to an undefined AA program; moreover, consistent with the rationalization hypothesis, we expected that the effect on opposition would be mediated through prejudiced individuals' tendency to construe the program as justice violating (i.e., merit or consistency violating ). In contrast to prejudice, we expected that justice beliefs would relate less strongly to opposition to an undefined program, because it does not explicitly violate justice principles.

\section{Method}

Our entire sample included 455 undergraduate students (229 men, 226 women) at the University of Waterloo, who participated for course credit. In fact, we conducted two studies ( $3 a$ and $3 b$ ) about four months apart, which built on one another (details follow). In the interest of parsimony, we present the analyses collapsed across sample where it is possible and appropriate to do so.

\section{Procedure}

In mass-testing sessions, we included the same measures used in Study 2 to assess prejudice (sexism and modern racism), BIM, and BIC. In addition, participants completed a questionnaire on AA that assessed their opinion of a "typical workplace AA program," as well as their construal of the typical program as merit and consistency violating. In the first sample $(N=324)$, our primary goal was to examine the roles of prejudice and justice beliefs as predictors of opposition. In a second sample $(N=131)$, we sought to replicate our initial findings and extend them by testing the construal question.

\section{Construal Measures}

We reworded the construal measures from Study 2 to fit the context of the typical versus specific AA programs. We created two items to assess perceptions of consistency violation (e.g., "Under a typical AA program, how likely is it that special training would be provided to target-group employees to help them develop job related skills necessary for advancement?"; "Under a typical AA program, how likely is it that a special mentorship program would be offered to target-group employees to help them succeed within an organization?"'); similarly, we created two items to assess merit violation (e.g., "Under a typical AA program, how likely is it that additional positions in an organization would be created for target-group applicants who are qualified but not among the top?"; "Under a typical AA program, how likely is it that a target-group applicant would be hired with little regard to his/her qualifications?"').

\section{Results and Discussion}

Preliminary examination of the predictors revealed similar results to that reported in Study 2. Namely, scores on BIM were unrelated to both BIC, $r(455)=-.08$, and prejudice, $r(455)$ $=.04$; scores on BIC were again weakly related to prejudice, $r(455)=.18, p<.01$, such that the more prejudiced the respondent, the more strongly he or she endorsed the consistency principle of procedural fairness. 


\section{Predicting Opposition to the Typical AA Program}

To examine the predictors of opposition to the typical AA program, we regressed participants' individual difference scores-prejudice, BIM, and BIC-on attitudes. Of the individual difference predictors, respondents' scores on prejudice were uniquely significantly correlated with opposition, $\beta=.28, p<$ .001 . The higher participants' scores on prejudice, the more they opposed the typical program. Relative to prejudice, justice beliefs were less strongly related to opposition (betas for BIC and BIM were -.01 and .12 , respectively). ${ }^{18}$

\section{Mediation of the Link Between Prejudice and Opposition to the Typical AA Program}

To investigate the mediating role of justice violation in the link between prejudice and opposition to the undefined AA program, we conducted a path analysis like those reported in Study 2 . We report the mediation analyses for Sample $3 b$ only because, as noted earlier, this sample contained the appropriate measures of construal ( see Method section). As shown in Figure 4 , the results are consistent with partial mediation. That is, the significant relation between prejudice and opposition was reduced when construal of the program as justice violating was controlled ( beta for total effect $=.30, p=.001$ versus beta for direct effect $=.20, p=.02$; the decrease in effect size was statistically significant, $z=2.56, p=.01$ ). The significant links between merit violation and both the predictor and the criterion implicate merit (vs. consistency) violation as the mediator in these data.

In summary, Study 3 showed that the greater people's level of prejudice, the more they construed the typical AA program as violating the merit principle; in turn, the more they opposed this undefined program.

\section{General Discussion}

Are people opposed to AA because they are prejudiced or because they perceive $A A$ to be unfair? Together, our data support the notion that the concern for justice is distinguishable

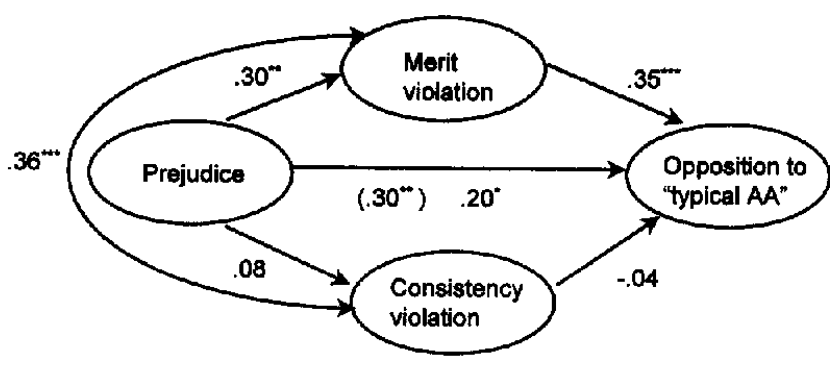

Figure 4. Path analysis depicting the mediating role of construal in the link between prejudice and opposition to an undefined affirmative action (AA) program in Study 3. Numbers on paths are betas. The total effect between the predictor and criterion (i.e., before controlling construal) is given inside parentheses; the direct effect (i.e., after controlling construal) is given outside parentheses. ${ }^{*} p<.05 .{ }^{* *} p<.01$. $* * * p<.001 . N=131$ from prejudice as a genuine source of opposition to AA. Nevertheless, we also found evidence consistent with the idea that prejudiced people might indeed rationalize opposition in the name of justice.

\section{The Concern for Justice as a Genuine Cause of Opposition}

It is unlikely that our justice findings can be interpreted as the mere rationalization of prejudiced individuals for two primary reasons: First, the effects of justice beliefs on attitudes were found with prejudice controlled statistically. Second, specific justice beliefs-BIM and BIC-each predicted opposition, as theoretically expected. When the program violated the merit principle, BIM predicted opposition uniquely. When the program violated the procedural justice rule of consistency, BIC was the strongest predictor. When it was clear that the program did not violate justice principles (the ET program) or when it was undefined (the typical AA program), justice beliefs were less pertinent. Taken together, the pattern of results is consistent with the idea that justice concerns can be a genuine cause of attitudes toward AA.

\section{The Concern for Justice as a Rationalization}

Nevertheless, we also found evidence to support the idea that, in some instances, justice-based opposition might indeed be a rationalization of underlying prejudice. Specifically, people scoring high and low on prejudice had different beliefs about a mild (i.e., nonpreferential) and undefined AA program, and these beliefs mediated the effect of prejudice on attitudes. It is interesting that beliefs about consistency violation mediated the relation between prejudice and opposition to the ET program in Study 2, whereas beliefs about merit violation mediated this relation in Study 3, where the program was undefined. Although we cannot be certain, it is possible that in Study 2 prejudiced individuals' construal of the ET program was limited to consistency violation, because we explicitly stated that the program did not violate merit ( see Kunda, 1990). In contrast, when the attitude object was ambiguous (Study 3), prejudiced people were systematically more likely than less prejudiced individuals to believe something more extreme-namely, that the program violated meritocracy.

Finally, given that the construal and attitude measures were

\footnotetext{
${ }^{18}$ In Study 3, there was a significant bivariate relation between gender and opposition to the typical program, $r(455)=-.26, p<.01$, with men reporting more oppasition than women. Thus, we entered gender and the interactions with gender in the analysis. We also entered sample and the Sample $\times$ Predictor interactions, to examine whether the results were moderated by sample. There were no significant interactions between the individual difference predictors and either gender or sample, indicating that the effects of the primary predictors were similar for men and women and across the two samples. Indeed, separate follow-up analyses conducted within sample and within gender consistently revealed a significant prejudice effect. The coefficient for the gender main effect did remain significant with all other variables controlled ( $\beta=$ $-.16, p<.01$ ), indicating that the effect of prejudice was not explained by gender. Given the significant unique effect of gender, gender was a covariate in the mediation analysis that follows.
} 
obtained concurrently, we cannot make firm conclusions regarding causality. That is, we do not know for certain whether construal influenced opposition, whether opposition influenced construal, or whether both occurred. Nevertheless, the results are consistent with the general idea that, in some cases, opposition in the name of justice can indeed be rooted in underlying prejudice.

\section{Strengths and Limits of the Research}

Given that our data are based on a convenience sample-in this case, university undergraduates - it is possible that our results might not generalize to all types of people. For example, one might argue that the "psychology" of attitudes toward AA could differ for individuals who are working full time, given that such people might have different experiences with AA than did our participants. Also, in view of the fact that our sample primarily comprised White respondents, it is possible that the results would differ for other racial or ethnic groups. In short, as in any convenience sample, we cannot make firm conclusions regarding the generalizability of our findings to all groups of people. It would be useful to investigate directly how the psychology of opposition that we have detailed here might differ as a function of theoretically meaningful respondent characteristics (e.g., race).

Several features of our design did, however, maximize internal validity, enabling us to make firmer conclusions about the roles of justice beliefs and prejudice as independent sources of opposition than is possible on the basis of the existing literature. First, we collected our individual difference data prior to attitudes, as well as in different settings. Second, we attempted to reduce spurious content overlap both among the predictors and between the predictors and the criterion, in the design phase. Third, we developed an elaborate paradigm that enhanced both experimental and mundane realism - in short, participants believed that their evaluations of the AA programs mattered. Indeed, although it was not a true behavioral measure ( such as a real vote), we created a situation in which participants' evaluations of the programs were as close to a vote as possible.

\section{Research Implications}

Our research has important implications for theory and research on attitudes toward AA. One obvious implication is that researchers should clearly specify the characteristics of the AA program under investigation, because, depending on what participants assume the characteristics of the AA program to be, results could differ substantially across investigations. Second, whereas we focused on three prototypical AA programs, there might be other programs, which vary on important psychological dimensions, to consider in future research. Third, although we focused primarily on investigating the independent roles of prejudice and justice beliefs as predictors of opposition to various AA programs, it is possible that other predictors might account for additional variance in opposition to specific programs. For example, future research might extend the psychology we have implicated here by examining the unique contribution of conservative versus liberal political ideology (e.g., Sidanius et al., 1996; Sniderman \& Piazza, 1993), self- and group interest (e.g., Kravitz et al., 1994; Tougas et al., 1991; Tougas et al., 1995), or social dominance orientation (e.g., Sidanius et al., 1996) in predicting opposition to certain AA programs (see also Clayton, 1996).

The marginally significant finding in Study 2 that perceptions of workplace discrimination mitigated adverse reactions to the violation of the consistency principle of procedural justice (i.e., the Tie program) among people who generally endorse this principle could have important implications: It might suggest that there may be specific beliefs that can override the usual effect of people's more distal justice values on opposition to certain social policies. Furthermore, in keeping with the idea of different determinants of attitudes, as a function of policy characteristics, it might be that different beliefs serve to mitigate opposition to the violation of different justice principles. For example, believing that workplace discrimination exists might be sufficient to justify inconsistent treatment (and therefore it might mitigate opposition to a policy, such as the Tie program) among those who generally value consistent treatment; however, it may not be sufficient to justify preferential treatment (and therefore a PT program) among those who generally value the merit principle. (Indeed, the results of an exploratory follow-up analysis in Study 2 indicated that the BIM $\times$ Discrimination interaction was not significant in the PT program.) However, future research is necessary to both follow up and extend our preliminary findings.

Finally, we used AA as an exemplar of a class of social policies where the concern for justice might be a cause of attitudes or a rationalization of other less socially desirable motivation. Consequently, our research framework might be used profitably in research on attitudes toward other social policies, such as immigration and bilingualism.

\section{Conclusion}

Our research suggests that the concern for justice and prejudice-two classes of determinants discussed widely in the literature-are distinguishable sources of opposition to AA. Each source was implicated, to a greater or lesser degree, as a function of the characteristics of the AA program. Together, our data are consistent with the notion that prejudiced individuals might oppose AA programs (more than less prejudiced individuals) through their tendency to construe them as violating justice principles, even though objectively the programs do not. Nevertheless, the data also support the notion that, independent of their level of prejudice, people can oppose AA programs that violate distributive and procedural justice norms as a result of genuine beliefs in the principles of fairness that the programs violate. In other words, although we found that prejudiced individuals might rationalize their opposition to $A A$ in the name of justice, it is not true that all justice effects are the mere rationalization of prejudiced individuals.

\section{References}

Adams, J. S. (1965). Inequity in social exchange. In L. Berkowitz (Ed.), Advances in experimental social psychology (Vol. 2, pp. 267-299). New York: Academic Press.

Aiken, L. S., \& West, G. (1991). Multiple regression: Testing and interpreting interactions. Newbury Park: Sage. 
Asch, S. E. (1948). The doctrine of suggestion, prestige, and imitation in social psychology. Psychological Review, 55, 256-277.

Barnes Nacoste, R. (1994). If empowerment is the goal . . . : Affirmative action and social interaction. Basic and Applied Social Psychol ogy, 15, 87-112.

Baron, R. M., \& Kenny, D. A. (1986). The moderator-mediator variable distinction in social psychological research: Conceptual, strategic, and statistical consideration. Journal of Personality and Social Psychology, 51, 1173-1182.

Beaton, A. M., Tougas, F., \& Joly, S. (1996). Neosexism among male managers: Is it a matter of numbers? Joumal of Applied Social Psychology, 26, 2189-2203.

Cattin, D. (1980). Estimation of the predictive power of a regression model. Journal of Applied Psychology, 65, 407-414.

Chacko, T. 1. (1982). Women and equal employment opportunity: Some unintended effects. Journal of Applied Psychology, 67, 119-123.

Clayton. S. (1996). Reactions to social categorization: Evaluating one argument against affirmative action. Journal of Applied Social Psychology, 26, 1472-1493.

Clayton, S. D., \& Tangri, S. S. (1989). The justice of affirmative action. In F. A. Blanchard \& F. J. Crosby (Eds.), Affirmative action in per. spective (pp. 177-192). New York: Springer-Verlag.

Cohen, J., \& Cohen, P. (1983). Applied multiple regression/correlation unalysis for the behavioral sciences ( 2 nd ed.). Hillsdale, NJ: Erlbaum.

Cohen, R. L. (1994). Some reffections on Smith and Crosby's "Affirmative action: Setting the record straight.' Social Justice Research, 7, 329-344.

Cropanzano, R., \& Ambrose, M. L. (in press). Procedural and distributive justice are more similar than you think: A monistic perspective and a research agenda. In J. Greenberg \& R. Cropanzano (Eds.), Advances in organizational justice. Lexington, MA: The New Lexington Press.

Cropanzano, R., \& Greenberg, J. (1997). Progress in organizational justice: Tunneling through the maze. In I. T. Robertson \& C. L. Cooper (Eds.), International review of industrial and organizational psychology, 1997 (Vol. 199, pp. 317-372). New York: Wiley.

Crosby, F. J. (1994). Understanding affirmative action. Basic and Applied Social Psychology, 15, 13-41.

Davey, L. M. (1995). Development and validation of two resource allocation surveys. Unpublished master's thesis, University of Waterloo, Waterloo, Ontario, Canada.

Davey, L. M., Bobocel, D. R., Son Hing, L. S., \& Zanna, M. P. (1998). The Belief in Merit Scale: An individual difference measure for social policy research. Manuscript submitted for publication.

Deutsch, M. (1975). Equity, equality, and need: What determines which value will be used as the basis of distributive justice? Journal of Social Issues, 31, 137-149.

Deutsch, M. (1985). Distributive justice: A social psychological perspective. New Haven, CT: Yale University Press.

Dovidio, J. F. (1996). Affirmative action and contemporary racial bias: Need resistance. Paper presented at the annual meeting of the American Psychological Association, Toronto, Ontario, Canada.

Esses, V. M., \& Seligman, C. (1996). The individual-group distinction in assessments of strategies to reduce prejudice and discrimination: The case of affirmative action. In R. M. Sorrentino \& E. T. Higgins (Eds.), Handbook of motivation and cognition: The interpersonal context (Vol. 3, pp. 570-590). New York: Guilford Press.

Fishbein, M., \& Ajzen, I. (1975). Belief, attitude, intention, and behavior: An introduction to theory and research. Reading, MA: AddisonWesley.

Gaertner, S. L., \& Dovidio, J. F. (1986). The aversive form of racism. In J. F. Dovidio \& S. L. Gaertner (Eds.), Prejudice, discrimination, and racism (pp. 61-89). Orlando, FL: Academic Press.
Goodman, L. A. (1960). On the exact variance of products. Joumal of the American Statistical Association, 55, 708--713.

Greenberg, J. (1993). The social side of faimess: Interpersonal and informational classes of organizational justice. In R. Cropanzano (Ed.), Justice in the workplace: Approaching fairness in human re. source management (pp. 79-103). Hillsdale, NJ: Erlbaum.

Greenberg, J., \& Cohen, R. L. (Eds.). (1982). Equity and justice in social behavior. New York: Academic Press.

Heilman, M. E. (1994). Affirmative action: Some unintended consequences for working women. In B. M. Staw \& L. L. Cummings (Eds.), Research in organizational behavior (Vol. 16, pp. 125-169). Greenwich, CT: JAI Press.

Homans, G. C. (1961). Social behavior: Its elementary forms. New York: Harcourt, Brace, \& World.

Jacobson, C. K. (1985). Resistance to affirmative action. Journal of Confict Resolution, 29, 306-329.

Kinder, D. R., \& Sanders, L. M. (1990). Mimicking political debate with survey questions: The case of White opinion on affirmative action for Blacks. Social Cognition, 8, 73-103.

Kinder, D. R., \& Sears, D. O. (1981). Prejudice and politics: Symbolic racism versus racial threats to the good life. Joumal of Personality and Social Psychology, 40, 414-431.

Kirk, R. E. (1982) . Experimental design: Procedures for the behavioral sciences (2nd ed.). Belmont, CA: Brooks/Cole.

Kleinpenning, G., \& Hagendoorn, L. (1993). Forms of racism and the cumulative dimension of ethnic attitudes. Social Psychology Quar. terly, 56, 21-36.

Kluegel, J. R., \& Smith, E. R. (1983). Affirmative action attitudes: Effects of self-interest, racial affect, and stratification beliefs on Whites' views. Social Forces, 61, 797-824.

Kravitz, D. A. (1995). Attitudes toward affirmative action plans directed at Blacks: Effects of plan and individual differences. Journal of Applied Social Psychology, 25, 2192-2220.

Kravitz, D. A., Harrison, D. A., Turner, M. E., Levine, E. L., Chaves, W., Brannick, M. T., Denning, D. L., Russell, C. J., \& Conrad, M. A. (1997). Affirmative action: A review of psychological and behavioral research. Bowling Green, $\mathrm{OH}$ : Society for Industrial and Organizational Psychology.

Kravitz, D. A., \& Platania, J. (1993). Attitudes and beliefs about racebased affirmative action: Effects of target and of respondent sex and ethnicity. Journal of Applied Psychology, 78, 928-938.

Kravitz, D. A., Stinson, V., \& Mello, E. W. (1994, August). Public reactions to affirmative action. In M. E. Turner (Chair), Affirmative action at work: Towards reducing barriers to the integrated workplace. Symposium conducted at the Fifth International Conference on Social Justice Research, Reno, NV.

Kunda, Z. (1990). The case for motivated reasoning. Psychological Bulletin, 108, 480-498.

Lea, J. A. (1995). Predicting support for affirmative action: The relative influence of procedural justice norms. Paper presented at the annual meeting of the Canadian Psychological Association, Charlottetown, Prince Edward Island, Canada.

Lerner, M. J. (1977). The justice motive: Some hypotheses as to its origins and its forms. Joumal of Personality, 45, 1-52.

Leventhal, G. S. (1980). What should be done with equity theory? New approaches to the study of fairness in social relationships. In K. Gergen, M. Greenberg, \& R. Wills (Eds.), Social exchange: Advances in theory and research (pp. 27-55). New York: Plenum

Leventhal, G. S., Karuza, J., \& Fry, W. R. (1980). Beyond fairness: A theory of allocation preferences. In G. Mikula (Ed.), Justice and social interaction (pp. 167-218). New York: Springer-Verlag.

Lind, E. A., \& Tyler, T. R. (1988). The social psychology of procedural justice. New York: Plenum.

McConahay, J. B. (1986). Modern racism, ambivalence, and the modern 
racism scale. In S. F. Dovidio \& S. L. Gaerner (Eds.), Prejudice, discrimination and racism: Theory and research (pp. 91-125). New York: Academic Press.

Murrell, A. J., Dietz-Uhler, B. L., Dovidio, J. F., Gaertner, S. L., \& Drout, C. (1994). Aversive racism and resistance to affirmative action: Perceptions of justice are not necessarily color blind. Basic and Applied Social Psychology, 15, 71-86.

Nacoste, R. W. (1985). Selection procedure and responses to affirmative action: The case of favorable treatment. Law and Human Behavior, 9. 225-242.

Nacoste, R. W. (1987). But do they care about fairness? The dynamics of preferential treatment and minority interest. Basic and Applied Social Psychology, 8, 177-191.

Nosworthy, G. J., Lea, J. A., \& Lindsay, R. C. L. (1995) . Opposition to affirmative action: Racial affect and traditional value predictors across four programs. Journal of Applied Social Psychology, 25, 314-337.

Pedhauzur, E. J. (1982). Multiple regression in behavioral research: Explanation and prediction (2nd ed.). Orlando, FL: Harcourt Brace.

Rasinski, K. A. (1987). What's fair is fair-or is it? Value differences underlying public views about social justice. Journal of Personality and Social Psychology, 53, 201-211.

Rubin, Z., \& Peplau, L. A. (1975). Who believes in a just world? Journal of Social Issues, 31, 65-89.

Sidanius, J., Pratto, F., \& Bobo, L. (1996). Racism, conservatism, affirmative action, and intellectual sophistication: A matter of principled conservatism or group dominance? Journal of Personality and Social Psychology, 70, 476-490.

Smith Winkelman, C., \& Crosby, F. J. (1994). Affirmative action: Setting the record straight. Social Justice Research, 7, 309-328.

Sniderman, P. M., \& Piazza, T. (1993). The scar of race. Cambridge, MA: Harvard University Press.
Son Hing, L. S. (1997). Opposition to affirmative action based an type of program, prior attitudes, and construals. Unpublished master's thesis, University of Waterloo, Waterloo, Ontario, Canada.

Stone, E. F. (1988). Moderator variables in research: A review and analysis of conceptual and methodological issues. In K. R. Rowland \& G. R. Ferris (Eds.), Research in personnel and human resources management. Greenwich, CT. JAI Press.

Thibaut, J., \& Walker, L. (1975). Procedural justice: A psychological analysis. Hillsdale, NJ: Erlbaum.

Tougas, F., Beaton, A. M., \& Veilleux, F. (1991). Why women approve of affirmative action: The study of a predictive model. International Journal of Psychology, 26, 761-776.

Tougas, F., Brown, R., Beaton, A. M., \& Joly, S. (1995). Neo-sexism: Plus ça change, plus c'est pareil. Personality and Social Psychology Bulletin, 2, 842-849.

Tougas, F., Joly, S., Beaton, A. M., \& St. Pierre, L. (1996). Reactions of beneficiaries to preferential treatment: A reality check. Human Relations, 49, 453-464.

Tougas, F., \& Veilleux, F. (1988). The influence of identification, collective relative deprivation, and procedure of implementation on women's response to affirmative action: A causal modeling approach. Canadian Journal of Behavioral Science, 20, 15-28.

Turner, M. E., \& Pratkanis, A. R. (1994). Affirmative action: Insights from social psychology and organizational research. Basic and Applied Psychology, 15, 1-11.

Tyler, T. R., \& Lind, E. A. (1992). A relational model of authority in groups. In M. P. Zanna (Ed.), Advances in experimental social psychology (Vol. 25, pp. 115-191). New York: Academic Press.

Received February 10, 1997

Revision received March 6, 1998 Accepted March 22, 1998 